\title{
A Multi-Center Retrospective Study of Clinical features, Laboratory Characteristics, and Outcomes of 325 Hospitalized Children with Coronavirus Disease 2019 (COVID-19); A Preliminary Report from Iranian Network for Research in Viral Diseases (INRVD)
}

Iraj Sedighi

hamadan university of medical sciences

Alireza Fahimzad

shahid beheshti university of medical sciences

Neda Pak

tehran university of medical sciences

Mitra Khalili

shahid beheshti university of medical sciences

Mohammad Reza Shokrollahi

Qom University of Medical Sciences and Health Services

Hosein Heydari

Qom University of Medical Sciences and Health Services

Zahra Movahedi

Qom University of Medical Sciences and Health Services

Anahita Sanaei Dashti

shiraz university of medical sciences

Fatemeh Cheraghali

golestan university of medical sciences

Ahmad Shamsizadeh

Ahvaz Jundishapur University: Ahvaz Jondishapour University of Medical Sciences

Mohammadreza Mirkarimi

Ahvaz Jundishapur University of Medical Sciences: Behbahan University of Medical Sciences

Mohsen Alisamir

ahvaz jundishapur university of medical sciences

Houman Hashemian

Guilan University of Medical Sciences

Jafar Soltani 
kurdistan university of medical sciences

\section{Ali Hosseininasab}

kerman university of medical sciences

\section{Abdolkarim Hamedi}

mashhad university of medical sciences

\section{Mohammad Sadegh Rezai}

mazandaran university of medical sciences

\section{Shirin Sayyahfar}

iran university of medical sciences

\section{Manijeh Kahbazi}

arak university of medical siences

\section{Aliakbar Abedini}

Tabriz university of medical siences

\section{Afsaneh Akhondzadeh}

arak university of medical sciences

\section{Hamid Reza Sherkatolabbasieh}

Lorestan university of medical sciences

\section{Ali Akbar Razlansari}

Lorestan university of medical sciences

\section{Mina Alibeik}

Shahid beheshti university of medical sciences

\section{Soheil Omid Malayeri}

Islamic azad university

\section{Zohreh Shalchi}

Hamadan university of medical sciences

\section{Ali Shahabinezhad}

Tehran university of medical sciences

\section{Parinaz Khalkhali Asl}

Golestan university of medical sciences

\section{Fatemeh Nafe Monfared}

Tehran university of medical sciences

\section{Shiva Maleki}

Tarbiat modares university

\section{Rezvan Kakavand}

Tarbiat modares university

\section{Mohammad Farahmand}

tehran university of medical sciences

\section{Babak Shahbaz}

Tehran university of medical sciences 


\section{Ahmad Tavakoli}

Iran University of Medical Sciences https://orcid.org/0000-0003-1857-0610

\section{Sara Akhavan Rezayat}

Tehran university of medical sciences

\section{Mohammad Reza Karimi}

Tehran university of medical sciences

\section{Ali Jafarpour}

Tehran university of medical sciences

\section{Saber Soltani}

Tehran university of medical sciences

\section{Azam Ghaziasadi}

Tehran university of medical sciences

\section{Razieh Dowran}

Tehran university of medical sciences

\section{Shohreh Azimi}

Tehran university of medical sciences

\section{Shima Sadeghipour Marvi}

Tehran university of medical sciences

\section{Foad Abazari}

Tehran university of medical sciences

\section{Seyed Mohammad Jazayeri ( $\nabla$ jazayerism@tums.ac.ir)}

Tehran University of Medical Sciences

\section{Research article}

Keywords: Severe Acute Respiratory Syndrome Coronavirus-2, COVID-19, Children

Posted Date: October 28th, 2020

DOl: https://doi.org/10.21203/rs.3.rs-96813/v1

License: (c) (i) This work is licensed under a Creative Commons Attribution 4.0 International License. Read Full License 


\section{Abstract}

Background: The objectives of this study were to analyze the clinical features and laboratory profiles and risk factors associated with critical illness of children with SARS-CoV-2.

Methods: 325 COVID-19 pediatric patients were recruited through a collaborative research network between March and May 2020. Demographics, clinical, laboratory, and radiological results were obtained from patient files.

Results: Of 325 patients, 189 (58\%) and $136(42 \%)$ were males and females, respectively. The mean age was $6.18 \pm 4.99 .195(60 \%)$ and 130 (40\%), had moderate and severe conditions, respectively. 45 (13.9\%) of patients died. The common symptoms were fever (72.6\%), cough (59\%) and shortness of breath (36\%). $254(78 \%)$ and 145 (44.6\% (had gastrointestinal and neurological symptoms, respectively. Shortness of breath, rhinorrhea, nausea/vomiting, decrease in platelet counts; increase values in C-reactive protein, lactate dehydrogenase (LDH), and blood urea nitrogen, decrease in the blood $\mathrm{PH}$ and $\mathrm{HCo} 3$ were significantly associated with the disease severity. $58.2 \%$ and $65.4 \%$ of patients showed abnormal radiographic appearance in Chest X-ray and in chest CT scan, respectively, which were correlated with disease severity. 104 (32\%) of patients referred to ICU. The coexistence of comorbidity was the main factor associated with ICU admission, shock, arrhythmia, acute kidney injury, acute respiratory distress syndrome (ARDS), acute cardiac injury, and death.

Conclusions: We describe a higher than previously recognized rate of COVID-19 mortality in Iranian pediatric patients. Epidemiological factors, such as relatively high case fatality rate in the country and the presence of underlying diseases are the main factors for the high death rate.

\section{Background}

Coronavirus disease 2019 (COVID-19), caused by the severe acute respiratory syndrome coronavirus 2 (SARS-CoV-2), emerged from Wuhan, Hubei province, China, in late 2019 and has been now rapidly spreading outside of China and globally to many countries across six continents. This phenomenon has evolved from an epidemic to a pandemic that attracted global attention, and WHO has declared the COVID-19 as a public health emergency of international concern on 30 January 2020 [1]. Patients infected with the virus may be asymptomatic; however, in more severe cases, infections causing viral interstitial pneumonia which may, in turn, lead to the severe acute respiratory syndrome, multiple organ failure in $10-15 \%$ of adults, and even death [2]. Interestingly, a majority of patients reported in the literature were adults. An analysis from a cohort study of 44672 confirmed cases in China has elucidated that only $1-2 \%$ of COVID-19 cases were children younger than 10 years old [3], and more than $90 \%$ of pediatric patients had mild or moderate disease with much fewer severe and critical cases (5.9\%) than adult patients (18.5\%) [3-8]. Therefore, for reasons that are yet to be clarified, the course of the disease in children seems to be generally mild compared to that seen in adults $[8,9]$. Several hypotheses have been proposed so far for the mildness nature of COVID-19 disease in pediatrics, including: highly effectiveness 
of innate immune response in this age groups [10], early childhood measles, mumps, and rubella (MMR) vaccination (due to molecular mimicry between amino acid residues) [11], memory to a cross-reactive antigen because of cross-reaction to related coronavirus strains from earlier infection (antibodydependent enhancement due to original antigenic $\sin$ ) [12], protection of children against COVID-19 as a result of cross-immunity due to previous exposure to seasonal coronavirus [13] and early childhood BCG vaccination which may induce trained immunity that could confer some protection for SARS-CoV-2 [14]. On the other hand, due to the aggressive nature of COVID-19, severe and fatal cases in children are expected to be continued and also to be increased due to its global spread along with the growing community transmission and overall current disease prevalence. Indeed, the proportions of severe and critical cases stratified by several age sub-categories obtained from a recent report from China on 2143 children with suspected COVID-19 were $10.6 \%$ for $<1$ year, $7.3 \%$ for $1-5$ years, $4.2 \%$ for $6-10$ years, $4.1 \%$ for $11-15$ years, and $3.0 \%$ for $\geq 16$ years [15]. In spite of that, data reported on pediatric COVID-19 patients are limited. Despite the worldwide spread, the epidemiological risk factors associated with disease severity and the incidence of critical illness of COVID-19 remain largely unclear among children.

The objectives of this study were (i) to analyze the epidemiological characteristics (ii) to describe the clinical features and laboratory profiles and (iii) to investigate the risk factors associated with critical illness of children with SARS-CoV-2 infection admitted to hospitals collaborative to the Iranian Network for Research in Viral Diseases (INRVD).

\section{Methods}

\section{Population and Settings}

The present study was a retrospective descriptive clinical study. Data were collected from a total of 325 cases through an extensive collaborative research network, including 15 general and pediatrics hospitals, coordinated by INRVD. We included all pediatric patients (aged 0-15 years) who were admitted to any of the recruiting centers between the $19^{\text {st }}$ of March to $31^{\text {st }}$ May 2020 and were diagnosed with COVID-19 (see below). Patients were screened for COVID-19 virus based on clinical manifestations at the initial presentation, or who underwent epidemiological investigation because of an exposure history to any epidemic region or close contact with known patients with confirmed COVID-19 within 14 days, especially within their family.

Nasal, oropharyngeal, or nasopharyngeal swab specimens were collected by trained personnel based on national guidelines issued by the Iranian Center for Disease Control (CDC) during the study period [16]. All samples referred to regional referral laboratories across the country using recommended real-time reverse transcriptase polymerase chain reaction (RT-PCR) assays [17]. Importantly, for a significant proportion of patients $(159,49 \%)$ who had negative results on the initial testing, the clinical, laboratory, and radiological assessment were carried out for COVID-19 diagnosis (see below). All enrolled patients in this investigation were diagnosed for COVID-19 according to the criteria formulated by the Iranian CDC. Subsequently, the severity of COVID-19 between subjects was classified into an asymptomatic infection, 
as mild, moderate, severe, or critical in line with clinical features, laboratory testing, and chest scan imaging. Both the laboratory-confirmed and suspected cases were included in the analysis, as follows.

1. For asymptomatic cases, individuals infected by SARS-CoV-2 without any clinical symptoms and signs throughout the course of the infection with or without abnormal chest CT imaging findings in the presence of a positive 2019-nCoV nucleic acid test result.

2. For mild cases, clinical symptoms of acute upper respiratory tract infection with or without fever, no radiographic findings of pneumonia. Some cases in this group might have only digestive symptoms.

3. For moderate cases, the diagnostic criteria: either has clinical signs and symptoms or frequent fever and cough, but no obvious hypoxemia. However, chest computed tomography showed lung abnormalities presenting pneumonia, which were subclinical.

4. For severe cases, the diagnostic criteria: (i) respiratory distress, tachypnea $\geq 60 / \mathrm{min}$ in neonates, $\geq$ $50 /$ min between 1 to 12 months, $\geq 40 / \mathrm{min}$ between 1 to 5 years old and $\geq 30 / \mathrm{min}$ older than 5 years old; (ii) hypoxemia, with resting oxygen saturation $\leqq 93 \%$; and (iii ) arterial partial oxygen pressure ( $\mathrm{PaO} 2$ )/oxygen absorption concentration (FiO 2 ) $\leqq 300 \mathrm{mmHg}$. The disease usually progressed at about 1 week, and dyspnea occurred with central cyanosis.

5. Critical: for children who quickly progressed to acute respiratory distress syndrome or respiratory failure required mechanical ventilation and might also have shock, encephalopathy, myocardial injury or heart failure, coagulation dysfunction, complicated with other organ failure requiring ICU care.

6- Diagnostic criteria for suspected cases were defined as (i) fever, respiratory, digestive symptoms (e.g. vomiting, nausea, and diarrhea), or fatigue; (ii) laboratory test showing decreased lymphocyte count (lymphopenia) or increased level of C-reactive protein; or (iii) abnormal chest radiograph imaging results.

The project was approved by the ethics committee of Tehran University of Medical Sciences (No. 1399.378) and followed the Declaration of Helsinki. Written consent was obtained from the guardians of the patients.

\section{Procedures}

\section{Laboratory indicators}

Laboratory examinations included routine testing and measurement of biomarkers for monitoring lung, liver, and renal functions together with hematologic parameters, were carried out within general hospitals laboratories using CE-IVD assays.

\section{Molecular Assays}

Screening for SARS-Cov-2 was performed for all pediatric cases admitted to the hospitals for the suspension of COVID-19 infection. According to Iranian CDC guidelines, COV-2 infection was confirmed by real-time reverse transcription polymerase chain reaction (RT-PCR) testing on throat specimens using 
flocked swabs, which were collected immediately upon the admission. Collaborative clinical virology is obliged to apply two sets of primers for two target genes (E and RdP genes). The Iranian Pasture Institute provided these dual-target detection kits along with a protocol for all laboratories across the country. For interpretation, the cut-off value was 40 cycle thresholds (Ct). A value of less than 37 was positive; a $\mathrm{Ct}$ value $>40$ was negative, and 37-40 was regarded as borderline results (the diagnosis needed to be repeated). If respiratory samples obtained from patients were successfully tested positive by either or both genes, the specimens were considered positive, and the case was considered laboratory-confirmed.

\section{Radiological Assessments}

According to the guidelines issued by The Ministry of Health, all COVID-19 confirmed cases with any respiratory symptoms undergo a chest X-ray upon admission. A chest CT scan usually applies in the case of either the presence of any abnormality in their X-ray or for the patients who progress to the severe form of the disease.

\section{Data collection}

Not too many hospitals are equipped with patients' electronic medical records. Therefore, demographic data, exposure and medical history, clinical signs and symptoms at presentation, laboratory examinations, imaging data, and treatments and outcomes on all pediatric patients admitted to the hospital during the study period were placed in a predefined, standardized, field-tested electronic form provided by INRVD. Filled forms were subsequently transferred into excel files at each hospital by trained individuals. Due to the heterogeneity of obtained results (especially for hematological and biochemical test results), all the files contained mismatched assays data were excluded from further analysis. After eliminating technical bias, a separate team was responsible for cleaning the data. These were reviewed for internal consistency or missing data by two trained researchers independently.

\section{Statistical analysis}

All statistical analyses were performed using Statistical Package for the Social Sciences (SPSS) for Windows release 25.0 (SPSS Inc., Chicago, IL, USA). Descriptive statistics were generated for demographic and clinical characteristics. Chi-square $\left(\chi^{2}\right)$ or Fisher's exact tests were also used to compare categorical variables. P-values less than 0.05 were considered to indicate significant statistically.

\section{Results}

\section{Demographic and medical past history data}

Of the total number of 325 pediatrics patients, $189(58 \%)$ and $136(42 \%)$ were males and females, respectively (Table 1). The age of subjects ranged between 0 and 15 years old; the mean age was $6.18 \pm$ 4.99. There was no significant correlation between the distributions of cases in different age groups ( $P$ - 
value 0.85 , Table 1 ). A majority of patients had a history of close contact with COVID-19 patients and/or travel to provinces with a high prevalence of COVID-19 (results not shown).

Regarding the vaccine history of patients, 300 (92.4\%) had received all routine childhood vaccines, and 25 (7.6\%) received incomplete vaccination in fear of high-risk disease transmission in the health care centers. Previous medications (before the admission), including antibiotic therapy, corticosteroid therapy, and chemotherapy were reported in $117(36 \%), 33(10.2 \%)$, and $32(9.8 \%)$ of patients, respectively (Table 1).

\section{Clinical Characteristics}

323 patients had at least one symptom before the admission, while only 2 of the cases did not have any symptoms. $236(72.6 \%)$ had a fever. The common respiratory symptoms were cough (59\%), shortness of breath $(36 \%)$, sore throat $(6.15 \%)$, and rhinorrhea (4\%). Gastrointestinal (GI) symptoms were seen in 254 (78\% (of patients including nausea/ vomiting (31.38\%), anorexia (26.8\%), diarrhea (13.84\%) and abdominal pain (6.15\%). 145 (44.6\%( of children had neurological symptoms including, fatigue (17.5\%), drowsiness/ loss of consciousness (12\%), seizure (6.15\%), headache $(5.8 \%)$ and myalgia $(3.07 \%)$. Eleven (3.38\%) of patients experienced different kinds of skin rash. Among the above symptoms, only shortness of breath and rhinorrhea were significantly associated with the disease severity ( $P$ values 0.001 and 0.033 , respectively, Table 1 ).

Upon clinical examination, grunting (P-value 0.004), intercostal and subcostal retractions ( $P$-value $<0.001$ ), nasal flaring ( $P$-value $<0.001)$, as well as respiratory fine crackles ( $P$ value 0.001$)$, were significantly associated with the disease severity (Table 1 ). Other signs including, wheezing, coarse respiratory crackles, and cyanosis, did not substantially correlate with disease severity (Table 1).

\section{Laboratory Data}

In the process of interpretation and analyzing the data, there was a high percentage of heterogeneity in the hematological and biochemistry results. Taken into consideration, to avoid any false data outputs, we have decided to exclude some of our unreliable results. As it can be clearly seen from the Table-1, the presented results have undergone excessive shrinkage.

166 (51\%) of patients showed positive RT results obtained from at least one of the upper respiratory tract specimens. 159 (49\%) of patients had negative PCR results on the initial testing. There was no significant association between the positivity of PCR results and the clinical outcome of subjects (P-value 0.5 , Table 1).

The hematological assessment showed that a decrease in platelet counts, together with increase Creactive protein values had substantial correlations with the disease outcomes ( $P$ values 0.015 and 0.038 , respectively, Table 1). Among a list of biochemistry results, only increased values of LDH (P value, 0.007) and blood urea nitrogen ( $P$ value, 0.003 ), showed insignificant associations with illness severity (Table 1). 


\section{Blood saturation results}

At the beginning of the pandemic and due to the shortage of facilities in some hospitals, blood saturation tests were carried only for 148 patients. A decrease in the blood $\mathrm{PH}$ and $\mathrm{HCO} 3$ was associated with the illness severity (P values 0.004 and 0.003 , respectively, Table 1). However, Po2 and PCo2 levels had no significant correlation with the disease outcome (Table 1).

\section{Radiological Findings}

Overall, of 232 patients who undertook chest X-ray, 58.2\% showed abnormal radiographic appearance, whereas, in the chest CT scan from 205 subjects, 65.4\% showed abnormal features. Statistics showed that both chest X-ray and CT scan abnormal results had significant correlations with disease severity ( $P$ values $<0.001$ and 0.029 , respectively, Table 1$)$. Ground glass opacity (44\%), lung consolidation ( $26 \%)$, peripheral airspace opacities (25\%), patchy infiltration (19\%), and pleural effusion (9\%), were the common radiological findings of which; the first two formers had significant correlations with illness severity $(P$ values 0.029 and 0.009 , respectively, results not shown).

\section{Clinical outcome}

Table 2 and figure 1 show the correlation between different age groups and disease severity. 195 (60\%) and $130(40 \%)$, had moderate and severe conditions, respectively (Table 1). No significant correlation was found between different age groups of patients and death (P-value 0.4, Table 2). In total, 135 (41.5\%) of patients had a history of at least one underlying disease. Table 1 describes the details of those morbidities. Malignancies (36, 26.6\%), and heart disease (14,10.3\%) were amongst the commonest comorbidities among the cases. Other morbidities were included: asthma $(6,4.44 \%)$, cystic fibrosis $(2$, $1.48, \%)$, chronic kidney diseases $(7,5 \%)$, diabetes $(2,1.48 \%)$, failure to thrive $(9,6.66 \%)$ and other medical conditions $(57,42.2 \%)$ (Table 1$) .45(13.9 \%)$ of patients died. The only significant criterion for deceased patients was the presence of comorbidity (P-value $<0.001$, Table 3 ).

Due to 104 (32\%) patients' critical condition, they were referred to ICU (Table 3). The only factor which was correlated with ICU referrals was the presence of comorbidity (P-value 0.003 , Table 3 ). No significant correlation was found between the age group and referral to ICU (P-value 0.2, Table 2). No other clinical symptoms, laboratory parameters, and radiological findings were associated with ICU admission (results not shown).

Oxygen therapy was used for 121 (37.2\%) of patients. 78 (24\%) of patients experienced at least one clinical severe outcome as the followings: ARDS 35 (10.7\%), shock 18 (5.5\%), acute cardiac injury 11 (3.38\%), arrhythmia 7 (2.2\%), and acute kidney injury 7 (2.2\%). Justification of these outcomes with the history of comorbidities showed that subjects who were had at least one underlying disease suffered from shock ( $P$ value, 0.003), arrhythmia ( $P$ value, 0.13$)$, acute kidney injury ( $P$ value, 0.13$)$, ARDS ( $P$ value, $<0.001$ ) and acute cardiac injury ( $P$ value, $0.057 \%$ ) 
Upon justifying with different age groups, ARDS's only occurrence showed a significant correlation ( $P$ value 0.015 , Table 2 ). No other clinical outcome or parameters was associated with the patients' age (Table 2).

\section{Treatment}

During hospitalization, $262(80.6 \%)$ patients received different antibiotics either for treatment or prophylaxis against bacterial infections. $72(22 \%)$ did not receive any treatment. Hydroxychloroquine was the basis and the drug of choice as the initial treatment in 208 (64\%) patients (Table 4). Different antivirals, with or without the combination of hydroxychloroquine or naproxen, were advocated for 253 $(78 \%)$ of patients with both moderate and severe conditions (Table 4). Nevertheless, for a majority of severe cases, different cocktails of drugs were used (Table 4). Even more, oseltamivir was prescribed for 27 (8.3\%) patients based on the initial suspension for influenza infection. However, in a majority of those included in the severe type of the disease, no significant improvements were seen for those who progressed to death (results not shown).

\section{Discussion}

The data on medical course and clinical outcomes of COVID-19, as well as predisposing factors regarding the prognosis of the disease is obscure. In the present multicenter, country-wide investigation, we summarized the clinical, laboratory, and radiographically data of 325 pediatric patients with laboratory and/or clinically confirmed COVID-19 infection. We found no correlation between age and gender and disease severity. However, the proportions of severe and critical cases stratified by several age sub-categories obtained from a recent report from China on 2143 children with suspected COVID-19 were $10.6 \%$ for $<1$ year, $7.3 \%$ for $1-5$ years, $4.2 \%$ for $6-10$ years, $4.1 \%$ for $11-15$ years, and $3.0 \%$ for $\geq$ 16 years (3). Present study showed that $49 \%$ of patients had negative PCR results on the initial testing. Another investigation from Poland revealed that only 3.26\% (15/459) of symptomatic pediatric patients were positive for SARS-CoV-2 [18]. The reasons for such high percentage of negative results in molecular testing deserves further clarification.

Our results showed that at the time of admission, fever (72.6\%), cough (59\%), shortness of breath (36\%), nausea/ vomiting (31.38\%), and anorexia (26.7\%) were the commonest symptoms. Similarly, fever, cough, shortness of breath, and dyspnea have been reported as the most common symptoms among admitted children to the hospitals in the USA [19] and China [20], respectively. Overall, in a systematic review published by Patel et al. of 633 patients from 10 studies, $296(46.7 \%)$ had a fever [21]. Other publications emphasized the presence of fever as well as respiratory symptoms among children with different proportions, especially in severe cases $[19,20,22]$. GI symptoms were seen in $78 \%$ of Iranian pediatrics. Nevertheless, in other publications from China and the USA, GI manifestations were reported at $8-29 \%$ [8, 22-24]. Patel et al. reported a prevalence of 128 (20\%) GI symptoms among 633 patients from 10 studies [21]. Cough and GI symptoms were common among severe cases in a systematic review and meta-analysis [8]. 
Neurological manifestations were observed in 44\% of Iranian COVID-19 infected children. Fatigue and myalgia were found at a similar proportion between moderate and severe cases. However, seizure and drowsiness or loss of consciousness were seen in severe more than moderate cases despite not being statistically significant ( $9.2 \%$ vs. $4.1 \%$ and $15 \%$ vs. $10 \%$, respectively). However, Yingying Lu reported that only 6 (5.5\%) of 110 children with COVID-19 from Wuhan had neurological symptoms [22]. In a systematic review and meta-analysis consisted of twenty-one studies/case series and five case reports (3707 patients) published earlier [25], headache, myalgia and fatigue were predominant as non-specific neurological manifestations, presenting altogether in $16.7 \%$ cases. Only $1 \%$ were found to have been reported with definite neurological complications, more in those suffering from a severe illness (like a seizure, $3.1 \%)$.

On the other hand, some authors reported that children with COVID-19 had less often symptoms (especially fever) $[26,27]$. Asymptomatic children have been observed in most of the published data so far ranged between $10 \%$ and $32 \%[8,21,22,26-28]$. One of the reasons for the presence of such symptomatic cases in our study (99.38\%) might be related to the fact that all collaborative hospitals in the present study were the referral centers for high-risk pediatrics admission. Due to the small size of articles released on COVID-19 infected children, it is difficult to draw any definite conclusion on the common symptoms that needed more attention to diagnose either ordinary versus severe cases at the time of presentation.

We observed more intercostal and subcostal retractions ( $P$ value, $<0.001)$, nasal flaring ( $P$ value, $<0.001)$ as well respiratory fine crackles (P value, 0.001$)$ in children with a severe form of the disease with different frequencies.

The hematological assessment showed that a decrease in platelet counts, together with increase Creactive protein values had substantial correlations with the disease's serious outcomes, a similar finding by Cao et al. from the USA [19]. Surprisingly, hemoglobin and WBC (including neutrophil and lymphocyte counts) were normal in a majority of Iranian COVID-19 infected children. Other studies emphasized the correlation between these values and the disease severity with different values [8, 22, 26, 27, 29].

Among a list of biochemistry results, only increased values of LDH and blood urea nitrogen, showed insignificant associations with disease severity. Consistent trends of elevated LDH and/or Alanine aminotransferase (ALT) values were found to be associated with disease severity [19,20,29]. A long list of abnormal laboratory parameters has been reported in several publications from different countries with a variety of heterogeneity between studies. However, no absolute biochemistry indexes have been found to be associated with disease severity so far.

Blood saturation tests were accomplished only for 148 patients. A decrease in the blood $\mathrm{PH}$ and $\mathrm{HCO} 3$ was associated with the disease severity. However, Po2 and PCo2 levels had no significant correlation with the disease outcome. Not too much data are available in the database to compare blood saturation values and the disease severity between COVID-19 positive children. 
In the chest X-ray, $55 \%$ and in chest CT scan, $25 \%$ of patients showed normal radiographic appearance. Normal radiological results among pediatrics COVID-19 patients results were found in 20\% [27], 27\% [8], $37.9 \%$ [22] and 42.9-45\% [21] of patients with confirmed COVID-19 disease. The present study showed that ground-glass opacity and lung consolidation showed significant correlations with disease severity. Similar findings were observed by others $[8,19,21,27]$. Two studies compared the radiological features between severe versus non-severe cases $[19,20]$. Both surveys found unilateral or bilateral opacities in CT scans of patients among two groups of patients. However, patchy consolidation was less frequently detected for non-severe children [20].

When justification was made between different age groups and clinical outcomes, with the exception of ARDS, no other complication was associated with age groups. Even more, admission to ICU and death was not related to a specific age group (P-values 0.2 and 0.4 , respectively).

Death rates are relatively few cases among children. A systematic review across 7 studies for which the information about mortality outcomes was available, there were a total of only 5 pediatric mortalities out of 2843 COVID-19 positive cases (0.0018\%) [21]. Among patients under 19 years old accounted for $2.2 \%$ of 44,672 confirmed cases, only one death was recorded (0.1\%) [30]. Basically, the crude mortality rate from COVID-19 in children is extremely low compared with that in current published data for adults $(2.3 \%$ e 14.6\%) [30-33]. To our surprise, the present study showed that $45(13.9 \%)$ of patients died. Reasons for such a high number of mortality might be due to: firstly, the selection bias of patients for admission. It has to be remembered that all the above-mentioned medical centers were the referral hospitals for very sick children across the country. Secondly, unawareness of medical staff for the nature of some patients' disease and mismanagement at the beginning of epidemics in Iran could be the other reason. Because of the absence of insights into the clinical outcome of COVID-19, especially multi-organ dysfunction, we did not assess the criteria for this observation due to the unknown features of the disease at the beginning of the epidemics. A majority of those cases are suspected of Kawasaki disease. Even more, Iranian pediatricians were surprised about the acquisition of Kawasaki among a higher age group ( $>5$ years old) children. Lastly, at the time of the preparation of this article, Iran still has been located at the top of the list of countries with a proportional high raw case fatality rate (CFR) in the world [34]. Although the true CFR ratio might not have known for some time, the estimated CFR among medically attended Iranian patients has been reported to be approximately $2 \%$ [35]. It should be acknowledged that, by contrast with other low mortality rate surveys, this investigation includes the patients from some provinces, which initially had a very high net reproductive number, which subsequently decreased after the passage of COVID-19 epidemic days. Nevertheless, the causes of death yet to be determined globally.

One of the critical criteria for COVID-19 adverse clinical outcomes in both childhood and adulthood patients includes the coexistence of underlying disease [36]. The presence of comorbidities has been the second cause (after age) of increased mortality and morbidity between adults with COVID-19 patients. There is not enough international data on the relation between specific morbidities and COVID-19 clinical outcomes and the definite pathogenesis is unknown. In the current survey, this was the main critical factor that showed a strong association with ICU admission, arrhythmia, ARDS, acute cardiac injury, and 
death. Conversely, Chang et al. observed that of 444 pediatric patients, 349 were reported to have no comorbidities (78.6\%) [8]. Wang Y et al. reported that 8 (22.9\%) of patients had underlying diseases [20]. Therefore, the comorbidity status was not a risk to develop the poorer outcome in these studies. Seven out of 20 pediatric patients in Xia's study had a previous history of congenital or acquired diseases; however, they did not mention about the outcome of these cases in their survey [27]. It is tempting to speculate that unlike the adults, underlying diseases are rare in children (such as diabetes mellitus, cardiovascular disease, or chronic kidney diseases). These underlying diseases may persuade patients to severe medical conditions during COVID-19.

Regarding the treatment options, as the basic drug of choice, hydroxychloroquine was used as the initial treatment advocated for 253 (78\%) of patients with and without different antivirals or naproxen for both moderate and severe conditions. Nevertheless, for a majority of severe cases, different cocktails of drugs were used. However, no significant improvements in the clinical course in a majority of severe patients, especially for those who progressed to death were seen.

\section{Conclusions}

In conclusion, the present study clearly showed that Iranian pediatric COVID-19 patients showed a remarkable high mortality rate. Epidemiological factors (such as relatively high case fatality rate, carelessness about infection control measures, etc.) and the presence of underlying diseases were the main factors for the high death rate. It is suggested that underlying coinfection may be more common in severe/fatal cases of COVID-19 between pediatrics. In contrast, hematological and biochemistry biomarkers in children are nonspecific and milder than that in adults. This information will pave the way for future studies on the pathogenesis of COVID-19 in pediatrics.

\section{Abbreviations}

LDH: Lactate dehydrogenase; ARDS: acute respiratory distress syndrome; COVID-19: Coronavirus disease 2019; SARS-CoV-2: Severe acute respiratory syndrome coronavirus 2; INRVD: Iranian Network for Research in Viral Diseases; RT-PCR: reverse transcriptase polymerase chain reaction; ALT: Alanine aminotransferase; CFR: case fatality rate; CRP: C-reactive protein; ESR: erythrocyte sedimentation rate; FTT: Failure to thrive; PT: Prothrombin Time; PTT = Partial Thromboplastin Time.

\section{Declarations}

\section{Ethics approval and consent to participate}

The project was approved by the ethics committee of Tehran University of Medical Sciences (No. 1399.378) and followed the Declaration of Helsinki. Written consent was obtained from the guardians of the patients.

\section{Consent for publication}


Not applicable

\section{Availability of data and materials}

All data generated or analyzed during this study are included in this article.

\section{Competing interests}

The authors have no conflict of interest.

\section{Funding}

This study was financially supported by Iranian Ministry of Health, grants No: 160200-1056-554 and 160200-1057-436.

\section{Authors 'contributions}

Study inception and design: S.M.J, I.S, A.F

Data collation: A.F, N.P, M.K, M.R.S, H. H, Z.M, A.S.D, F.C, A.S, M.M, M.A, H.H, J.S, A.H, A.H, M.S.R, S.S, M.K, A.A, A.A, H.R.S, A.A.R, M.A, S.O.M, Z.S, A.S.

Statistical analysis: M.F

\section{Drafting of the manuscript:}

Sorting data: P.K.A, F.N.M, S.M, R.K

Interpretation of data: B.S, A.T, S.A.R, M.R.K, A.J, S.S, A.G, R.D, S.A, S.S.M, F.A

Supervision: S.M.J, I.S

All authors have read and approved the manuscript.

\section{Acknowledgements}

Iranian Network for Research in Viral Diseases (INRVD) acknowledge the help of staff members of the collaborated hospitals including and virology student volunteers during the data entering phase of the study including: Mofid Children Hospital, Tehran; Nemazee Hospital, Shiraz; Imam Khomeini Hospital, Tehran; Aboozar Children' Hospital, Ahvaz; Be'sat Hospital, Hamadan; Taleqani Hospital, Arak; Be'sat Hospital, Sanandaj; Shahrivar Children's Hospital, Rasht; Ibn-Sina Hospital Sari; Ali Asghar Children's Hospital, Tehran; Children's Hospital, Tabriz; Shahid Rahimi Hospital of Khorramabad, Khorramabad; Masoumeh Children Hospital(Khorrami),Qom.

\section{References}


1. World Health Organization. Statement on the second meeting of the International Health Regulations (2005) Emergency Committee regarding the outbreak of novel coronavirus (2019-nCoV). Available at: https://www.who.int/news-room/detail/30-01-2020-statement-on-the-second-meeting-of-theinternational-health-egulations-(2005)-emergency-committee-regarding-the-outbreak-of-novelcoronavirus-(2019-nCov).

2. WHO-China Joint Mission, Report of the WHO-China Joint Mission on Coronavirus Disease 2019 (COVID-19), (2020). https://www.who.int/docs/default-source/cor-onaviruse/who-china-jointmission-on-covid-19-final-report.pdf (accessed March 1,2020).

3. Dong Y, Mo X, Hu Y, Qi X, Jiang F, Jiang Z, et al. Epidemiology of COVID-19 among children in China. Pediatrics. 2020;145:1-10.

4. Qiu H, Wu J, Hong L, Luo Y, Song Q, Chen D. Clinical and epidemiological features of 36 children with coronavirus disease 2019 (COVID-19) in Zhejiang, China: an observational cohort study. Lancet Infect Dis. 2020.

5. Novel CPERE. The epidemiological characteristics of an outbreak of 2019 novel coronavirus diseases (COVID-19) in China. Zhonghua Liu Xing Bing Xue Za Zhi. 2020;41:145-151.

6. Surveillances V. The epidemiological characteristics of an outbreak of 2019 novel coronavirus diseases (COVID-19)-China, 2020. China CDC Weekly. 2020;2:113-22.

7. Mogharab V, Pasha AMK, Javdani F, Hatami N. The first case of COVID-19 infection in a 75-day-old infant in Jahrom City, south of Iran. J Formos Med Assoc. 2020;119:995-997.

8. Chang T-H, Wu J-L, Chang L-Y. Clinical characteristics and diagnostic challenges of pediatric COVID19: A systematic review and meta-analysis. J Formos Med Assoc. 2020; 119: 982-989.

9. Henry BM, Lippi G, Plebani M. Laboratory abnormalities in children with novel coronavirus disease 2019. Clin Chem Lab Med. 2020; ;58:1135-1138.

10. Prompetchara E, Ketloy C, Palaga T. Immune responses in COVID-19 and potential vaccines: Lessons learned from SARS and MERS epidemic. Asian Pac J Allergy Immunol. 2020;38:1-9.

11. Sidiq KR, Sabir DK, Ali SM, Kodzius R. Does Early Childhood Vaccination Protect Against COVID-19? Front Mol Biosci. 2020;7:1-6.

12. Fierz W, Walz B. Antibody dependent enhancement due to original antigenic sin and the development of SARS. Front Immunol. 2020;11:1-5.

13. Devulapalli CS. COVID-19 is milder in children possibly due to cross immunity. Acta Paediatr. 2020. doi: 10.1111/apa.15407 [Epub ahead of print]

14. Covián C, Retamal-Díaz A, Bueno SM, Kalergis AM. Could BCG vaccination induce protective trained immunity for SARS-CoV-2? Front Immunol. 2020;11:1-7.

15. Dong Y, Mo X, Hu Y, Qi X, Jiang F, Jiang Z, et al. Epidemiological characteristics of 2143 pediatric patients with 2019 coronavirus disease in China. Pediatrics. 2020. https://doi.org/10.1542/peds.2020-0702.

16. http://medcare.behdasht.gov.ir/index.aspx?siteid=312\&fkeyid=\&siteid=312\&pageid=61966. 
17. World Health Organization (WHO). Laboratory testing for coronavirus disease 2019 (COVID-19) in suspected human cases: interim guidance, 2 March 2020. World Health Organization; 2020.

18. Kuchar E, Załęski A, Wronowski M, Krankowska D, Podsiadły E, Brodaczewska K, et al. Children were less frequently infected with SARS-CoV-2 than adults during 2020 COVID-19 pandemic in Warsaw, Poland. Eur J Clin Microbiol Infect Dis. 2020:1-7.

19. Chao JY, Derespina KR, Herold BC, Goldman DL, Aldrich M, Weingarten J, et al. Clinical characteristics and outcomes of hospitalized and critically ill children and adolescents with coronavirus disease 2019 (COVID-19) at a Tertiary Care Medical Center in New York City. J Pediatr. 2020;223:14-19.

20. Wang Y, Zhu F, Wang C, Wu J, Liu J, Chen X, et al. Children Hospitalized With Severe COVID-19 in Wuhan. Pediatr Infect Dis J. 2020;39:e91-e4.

21. Patel NA. Pediatric COVID-19: Systematic review of the literature. Am J Otolaryngol. 2020:102573.

22. Lu Y, Li Y, Deng W, Liu M, He Y, Huang L, et al. Symptomatic infection is associated with prolonged duration of viral shedding in mild coronavirus disease 2019: a retrospective study of 110 children in Wuhan. Pediatr Infect Dis J. 2020;39:e95-e9.

23. Hurst JH, Heston SM, Chambers HN, Cunningham HM, Price MJ, Suarez L, et al. SARS-CoV-2 Infections Among Children in the Biospecimens from Respiratory Virus-Exposed Kids (BRAVE Kids) Study. medRxiv. 2020.

24. Covid C, COVID C, COVID C, Bialek S, Gierke R, Hughes M, et al. Coronavirus Disease 2019 in Children -United States, February 12-April 2, 2020. MMWR Morb Mortal Wkly Rep. 2020;69:422.

25. Panda PK, Sharawat IK, Panda P, Natarajan V, Bhakat R, Dawman L. Neurological Complications of SARS-CoV-2 Infection in Children: A Systematic Review and Meta-Analysis. J Trop Pediatr. 2020; Epub ahead of print.

26. Bai K, Liu W, Liu C, Fu Y, Hu J, Qin Y, et al. Clinical Analysis of 25 COVID-19 Infections in Children. Pediatr Infect Dis J. 2020;39:e100-e3.

27. Xia W, Shao J, Guo Y, Peng X, Li Z, Hu D. Clinical and CT features in pediatric patients with COVID-19 infection: Different points from adults. Pediatr Pulmonol. 2020;55:1169-74.

28. Bai HX, Hsieh B, Xiong Z, Halsey K, Choi JW, Tran TML, Pan I, Shi LB, Wang DC, Mei J, Jiang XL, Zeng QH, Egglin TK, Hu PF, Agarwal S, Xie FF, Li S, Healey T, Atalay MK, Liao WH. Performance of Radiologists in Differentiating COVID-19 from Non-COVID-19 Viral Pneumonia at Chest CT. Radiology. 2020;296:E46-E54.

29. Henry BM, Vikse J. Clinical Characteristics of Covid-19 in China N Engl J Med. 2020;382:1860-1.

30. Wu Z, McGoogan JM. Characteristics of and important lessons from the coronavirus disease 2019 (COVID-19) outbreak in China: summary of a report of 72314 cases from the Chinese Center for Disease Control and Prevention. Jama. 2020;323:1239-42.

31. Chen N, Zhou M, Dong X, Qu J, Gong F, Han Y, et al. Epidemiological and clinical characteristics of 99 cases of 2019 novel coronavirus pneumonia in Wuhan, China: a descriptive study. Lancet. 2020;395:507-13. 
32. Huang C, Wang Y, Li X, Ren L, Zhao J, Hu Y, et al. Clinical features of patients infected with 2019 novel coronavirus in Wuhan, China. Lancet. 2020;395:497-506.

33. Wang D, Hu B, Hu C, Zhu F, Liu X, Zhang J, et al. Clinical characteristics of 138 hospitalized patients with 2019 novel coronavirus-infected pneumonia in Wuhan, China. Jama. 2020;323:1061-9.

34. Fan G, Yang Z, Lin Q, Zhao S, Yang L, He D. Decreased Case Fatality Rate of COVID-19 in the Second Wave: a study in 53 countries or regions Transboundary and emerging diseases. Transbound Emerg Dis. 2020. doi:10.1111/tbed.13819.

35. Lipsitch M, Swerdlow DL, Finelli L. Defining the epidemiology of Covid-19-studies needed. N Engl J Med. 2020;382:1194-6.

36. Hui DS, Azhar El, Madani TA, Ntoumi F, Kock R, Dar O, et al. The continuing 2019-nCoV epidemic threat of novel coronaviruses to global health-The latest 2019 novel coronavirus outbreak in Wuhan, China. Int J Infect Dis. 2020;91:264-6.

\section{Tables}

Table 1. Demographical, clinical, laboratory, and radiological of Pediatric Patients with Coronavirus Disease 2019 on Admission to the Hospital and Comparison with disease severity. 


\begin{tabular}{|c|c|c|c|c|}
\hline Characteristic & $\begin{array}{l}\text { Total* } \\
\text { N (\%) }\end{array}$ & $\begin{array}{l}\text { Moderate, } \\
\mathrm{N}=195^{1}\end{array}$ & $\begin{array}{l}\text { Severe, } \\
N=130^{1}\end{array}$ & p-value ${ }^{2}$ \\
\hline Age (Year) & \multicolumn{3}{|l|}{325} & 0.85 \\
\hline $0-1$ & $57(17.5)$ & $32(16)$ & $25(20)$ & \\
\hline \multirow[t]{2}{*}{$1-5$} & 104 & $65(33)$ & $39(31)$ & \\
\hline & \multicolumn{4}{|l|}{ (32) } \\
\hline \multirow[t]{2}{*}{$10-18$} & 94 & $59(30)$ & $35(28)$ & \\
\hline & \multicolumn{4}{|l|}{$(28.9)$} \\
\hline \multirow[t]{2}{*}{$5-10$} & 70 & $43(22)$ & $27(21)$ & \\
\hline & \multicolumn{4}{|l|}{$(21.5)$} \\
\hline Sex & \multicolumn{3}{|l|}{325} & 0.2 \\
\hline Female & $136(42)$ & $76(39)$ & $60(46)$ & \\
\hline Male & $189(58)$ & $119(62.9)$ & $70(54)$ & \\
\hline Underlying Diseases & \multicolumn{3}{|l|}{325} & 0.001 \\
\hline Negative & $190(58.4)$ & $128(66)$ & $62(48)$ & \\
\hline Asthma & $6(1.8)$ & $4(2.1)$ & $2(1.5)$ & \\
\hline CF & $2(0.6)$ & $2(1.0)$ & $0(0)$ & \\
\hline Chronic kidney disease & $7(2.1)$ & $1(0.5)$ & $6(4.6)$ & \\
\hline Diabetes & $2(0.6)$ & $2(1.0)$ & $0(0)$ & \\
\hline FTT & $9(2.7)$ & $4(2.1)$ & $5(3.8)$ & \\
\hline Heart Disease & $14(10.3)$ & $4(2.1)$ & $10(7.7)$ & \\
\hline Immunodeficiency & $2(0.6)$ & $0(0)$ & $2(1.5)$ & \\
\hline Malignancy & $36(11.0)$ & $23(12)$ & $13(10)$ & \\
\hline Others & $57(17.5)$ & $27(14)$ & $30(23)$ & \\
\hline History of Medication & 325 & & & \\
\hline Antibiotic & & & & 0.028 \\
\hline Negative & $208(64.0)$ & $115(59)$ & $93(72)$ & \\
\hline Positive & $117(36.0)$ & $80(41)$ & $37(28)$ & \\
\hline Corticosteroid & & & & 0.2 \\
\hline
\end{tabular}




\begin{tabular}{|c|c|c|c|c|}
\hline Negative & $292(89.4)$ & $179(92)$ & $113(87)$ & \\
\hline Positive & $33(10.1)$ & $16(8.2)$ & $17(13)$ & \\
\hline Chemotherapy & 325 & & & $>0.9$ \\
\hline Negative & $293(90.1)$ & $176(90)$ & $117(90)$ & \\
\hline Positive & $32(9.8)$ & $19(9.8)$ & $13(10)$ & \\
\hline Symptoms (At Admission) & 325 & & & \\
\hline Fever & & & & 0.6 \\
\hline Negative & $89(27.3)$ & $51(26)$ & $38(29)$ & \\
\hline Positive & $236(72.6)$ & $144(74)$ & $92(71)$ & \\
\hline Cough & & & & 0.3 \\
\hline Negative & $133(40.9)$ & $75(38)$ & $58(45)$ & \\
\hline Positive & $192(59.0)$ & $120(62)$ & $72(55)$ & \\
\hline Sore Throat & & & & 0.2 \\
\hline Negative & $305(93.8)$ & $180(92)$ & $125(96)$ & \\
\hline Positive & $20(6.1)$ & $15(7.7)$ & $5(3.8)$ & \\
\hline Shortness of Breath & & & & 0.001 \\
\hline Negative & $208(64.0)$ & $139(71)$ & $69(53)$ & \\
\hline Positive & $117(36.0)$ & $56(29)$ & $61(47)$ & \\
\hline Rhinorrhea & & & & 0.033 \\
\hline Negative & $312(96.0)$ & $183(94)$ & $129(99)$ & \\
\hline Positive & $13(4.0)$ & $12(6.2)$ & $1(0.8)$ & \\
\hline Fatigue & & & & 0.8 \\
\hline Negative & $268(82.4)$ & $162(83)$ & $106(82)$ & \\
\hline Positive & 57 & $33(17)$ & $24(18)$ & \\
\hline & $(17.5)$ & & & \\
\hline Myalgia & & & & $>0.9$ \\
\hline Negative & 315 (96.9) & 189 (97) & $126(97)$ & \\
\hline \multirow[t]{2}{*}{ Positive } & 10 & $6(3.1)$ & $4(3.1)$ & \\
\hline & (3) & & & \\
\hline
\end{tabular}




\begin{tabular}{|c|c|c|c|c|}
\hline Drowsiness/Loss Of Consciousness & & & & 0.3 \\
\hline Negative & $286(88)$ & $175(90)$ & $111(85)$ & \\
\hline Positive & 39 & $20(10)$ & $19(15)$ & \\
\hline & $(12)$ & & & \\
\hline Headache & & & & 0.3 \\
\hline Negative & 306 & $181(93)$ & $125(96)$ & \\
\hline & $(94.1)$ & & & \\
\hline Positive & 19 & $14(7.2)$ & $5(3.8)$ & \\
\hline & $(5.8)$ & & & \\
\hline Seizures & & & & 0.10 \\
\hline Negative & 305 & $187(96)$ & $118(91)$ & \\
\hline & $(93.8)$ & & & \\
\hline Positive & 20 & $8(4.1)$ & $12(9.2)$ & \\
\hline & $(6.1)$ & & & \\
\hline Abdominal Pain & & & & 0.5 \\
\hline Negative & 305 & $181(93)$ & $124(95)$ & \\
\hline & $(93.8)$ & & & \\
\hline Positive & 20 & $14(7.2)$ & $6(4.6)$ & \\
\hline & $(6.1)$ & & & \\
\hline Diarrhea & & & & 0.6 \\
\hline Negative & 280 & $170(87)$ & $110(85)$ & \\
\hline & $(86.1)$ & & & \\
\hline Positive & 45 & $25(13)$ & $20(15)$ & \\
\hline & $(13.8)$ & & & \\
\hline Nausea/ Vomiting & & & & 0.12 \\
\hline Negative & 223 & $127(65)$ & $96(74)$ & \\
\hline & $(68.6)$ & & & \\
\hline Positive & 102 & $68(35)$ & $34(26)$ & \\
\hline & (31.3) & & & \\
\hline Anorexia & & & & 0.7 \\
\hline
\end{tabular}




\begin{tabular}{|c|c|c|c|c|}
\hline \multirow[t]{2}{*}{ Negative } & 238 & $141(72)$ & \multirow[t]{2}{*}{$97(75)$} & \\
\hline & (73.2) & & & \\
\hline \multirow[t]{2}{*}{ Positive } & 87 & $54(28)$ & $33(25)$ & \\
\hline & $(26.8)$ & & & \\
\hline Skin Rash & & & & 0.12 \\
\hline Negative & 314 (96.6) & $191(98)$ & $123(95)$ & \\
\hline Positive & $11(3.3)$ & $4(2.1)$ & $7(5.4)$ & \\
\hline Clinical Signs & 325 & & & \\
\hline Cyanosis & & & & 0.2 \\
\hline Negative & 301 (92.6) & $184(94)$ & $117(90)$ & \\
\hline Positive & $24(7.3)$ & $11(5.6)$ & $13(10)$ & \\
\hline Grunting & & & & 0.004 \\
\hline Negative & 308 (94.7) & $191(98)$ & $117(90)$ & \\
\hline Positive & $17(5.2)$ & $4(2.1)$ & $13(10)$ & \\
\hline Nasal Flaring & & & & $<0.001$ \\
\hline Negative & $295(90.7)$ & $189(97)$ & $106(82)$ & \\
\hline Positive & $30(9.2)$ & $6(3.1)$ & $24(18)$ & \\
\hline Wheezing & & & & 0.9 \\
\hline Negative & 302 (92.9) & $182(93)$ & $120(92)$ & \\
\hline Positive & $23(7.07)$ & $13(6.7)$ & $10(7.7)$ & \\
\hline Intercostal and Subcostal Retractions & & & & $<0.001$ \\
\hline Negative & $252(77.5)$ & $171(88)$ & $81(62)$ & \\
\hline Positive & $73(22.4)$ & $24(12)$ & $49(38)$ & \\
\hline Respiratory Fine Crackles & & & & 0.001 \\
\hline Negative & $268(82.4)$ & $172(88)$ & $96(74)$ & \\
\hline Positive & $57(17.5)$ & $23(12)$ & $34(26)$ & \\
\hline Respiratory Coarse Crackles & & & & 0.5 \\
\hline Negative & $284(87.3)$ & $173(89)$ & $111(85)$ & \\
\hline Positive & $41(12.6)$ & $22(11)$ & 19 (15) & \\
\hline
\end{tabular}


Laboratory Data

PCR

Negative

Positive

WBC (/Cumm³)

Decreased

Increased

Normal

Neutrophils

Decreased

Increased

Normal

Lymphocytes

Decreased

Increased

Normal

Hemoglobin $(\mathrm{g} / \mathrm{dL})$

Decreased

Increased

Normal

Platelets (1000/Cumm)

Decreased

Increased

Normal

PT (seconds)

Decreased

Increased

Normal

PTT (seconds)
325

$159(48.9) \quad 99(51)$

$166(51.0) \quad 96(49)$

325

$78(24.0) \quad 46(24)$

$42(12.9) \quad 20(10)$

$205(63.0) \quad 126(66)$

325

33 (10.1)

51 (15.6)

241 (74.1)

325

102 (31.3)

18 (5.5)

205 (63.0)

325

155 (47.6)

3 (0.9)

167 (51.3)

325

60 (18.4)

106 (32.6)

159 (48.9)

97

2 (1.3)

0 (0)

13 (32)

28 (68)

64 (65.9)

97
0.5

60 (46)

70 (54)

0.25

32 (24)

22 (17)

79 (60)

0.004

7 (5.5)

29 (22)

96 (73)

0.55

45 (34)

8 (6.1)

78 (60)

0.058

71 (56)

1 (0.8)

56 (43)

0.015

26 (19)

54 (41)

53 (40)

0.6

2 (3.6)

18 (32)

36 (64)

$\begin{array}{lll}31(31.9) & 13(32) & 18(32) \\ 64(65.9) & 28(68) & 36(64)\end{array}$

Page 22/31 


\begin{tabular}{|c|c|c|c|c|}
\hline Decreased & $48(49.4)$ & $20(48)$ & $28(51)$ & \\
\hline Increased & $18(18.5)$ & $10(24)$ & $8(15)$ & \\
\hline Normal & $31(31.9)$ & $12(29)$ & $19(35)$ & \\
\hline International Normalized ratio (INR) & 97 & & & 0.21 \\
\hline Increased & $24(24.7)$ & $8(19)$ & $16(30)$ & \\
\hline Normal & $73(75.2)$ & $35(81)$ & $38(70)$ & \\
\hline $\mathrm{CRP}(\mathrm{mg} / \mathrm{dL})$ & 148 & & & 0.038 \\
\hline Increased & $115(77.7)$ & $72(73)$ & $43(88)$ & \\
\hline Normal & $33(22.2)$ & $27(27)$ & $6(12)$ & \\
\hline ESR (mm/hour) & 325 & & & $>0.9$ \\
\hline Increased & $123(44.8)$ & $75(44)$ & $48(44)$ & \\
\hline Normal & $156(55.9)$ & $96(56)$ & $60(56)$ & \\
\hline $\mathrm{BUN}(\mathrm{mg} / \mathrm{dL})$ & 325 & & & 0.003 \\
\hline Increased & $68(20.9)$ & $28(15)$ & $40(31)$ & \\
\hline Normal & $257(79.0)$ & $168(85)$ & $89(69)$ & \\
\hline Creatinine $(\mathrm{mg} / \mathrm{dL})$ & 325 & & & $>0.9$ \\
\hline Increased & $113(40.5)$ & $67(41)$ & $46(40)$ & \\
\hline Normal & 166 (59.4) & $98(59)$ & $68(60)$ & \\
\hline $\mathrm{Na}(\mathrm{mg} / \mathrm{dL})$ & 279 & & & 0.14 \\
\hline Decreased & $29(10.3)$ & $15(9)$ & $14(12)$ & \\
\hline Increased & $2(0.71)$ & $0(0)$ & $2(1.8)$ & \\
\hline Normal & 248 (88.8) & $151(91)$ & $97(86)$ & \\
\hline $\mathrm{K}(\mathrm{mg} / \mathrm{dL})$ & 279 & & & 0.11 \\
\hline Decreased & $16(5.7)$ & $9(5.0)$ & $7(6.2)$ & \\
\hline Increased & 38 (13.6) & $17(10)$ & $21(19)$ & \\
\hline Normal & $225(80.6)$ & $141(85)$ & $84(75)$ & \\
\hline $\mathrm{LDH}(\mathrm{mg} / \mathrm{dL})$ & $2(1.2)$ & $0(0)$ & $2(2.9)$ & 0.007 \\
\hline Decreased & $114(69.0)$ & $60(62)$ & $54(78)$ & \\
\hline
\end{tabular}




\begin{tabular}{|c|c|c|c|c|}
\hline Increased & $49(29.6)$ & $36(38)$ & $13(19)$ & \\
\hline Normal & 97 & & & \\
\hline $\mathrm{CPK}(\mathrm{mg} / \mathrm{dL})$ & $43(44.3)$ & $22(38)$ & $21(54)$ & 0.12 \\
\hline Increased & $54(55.6)$ & $36(62)$ & $18(46)$ & \\
\hline Normal & 165 & & & \\
\hline AST (mg/dL) & $58(35.1)$ & $33(33)$ & $25(38)$ & 0.7 \\
\hline Increased & $107(64.8)$ & $66(67)$ & $41(62)$ & \\
\hline Normal & 165 & & & \\
\hline $\operatorname{ALT}(\mathrm{mg} / \mathrm{dL})$ & $4(2.4)$ & $2(2.0)$ & $2(3.0)$ & $>0.9$ \\
\hline Decreased & $42(25.4)$ & $25(26)$ & $17(26)$ & \\
\hline Increased & $119(72.1)$ & $72(72)$ & $47(71)$ & \\
\hline Normal & 35 & & & \\
\hline Alkaline Phosphatase (mg/dL) & $6(17.1)$ & $4(14)$ & $2(29)$ & 0.8 \\
\hline Decreased & $6(17.1)$ & $5(18)$ & $1(14)$ & \\
\hline Increased & $23(65.7)$ & $19(68)$ & $4(57)$ & \\
\hline Normal & 35 & & & \\
\hline Bilirubin Direct (mg/dL) & $18(51.4)$ & $10(50)$ & $8(53)$ & 0.84 \\
\hline Increased & $17(48.5)$ & $10(50)$ & $7(47)$ & \\
\hline Normal & 35 & & & \\
\hline Bilirubin Total (mg/dL) & $11(31.4)$ & $4(22)$ & $7(41)$ & 0.3 \\
\hline Increased & $24(68.5)$ & $14(78)$ & $10(59)$ & \\
\hline Normal & 148 & & & \\
\hline $\mathrm{Ca}(\mathrm{mg} / \mathrm{dL})$ & 75 & $36(51)$ & $39(50)$ & 0.79 \\
\hline Decreased & 2 & $1(1.4)$ & $1(1.2)$ & \\
\hline Increased & 71 & $33(47)$ & $38(49)$ & \\
\hline Normal & 35 & & & \\
\hline$P(\mathrm{mg} / \mathrm{dL})$ & $28(80.0)$ & $21(75)$ & $7(100)$ & 0.33 \\
\hline Decreased & $5(14.2)$ & $5(18)$ & $0(0)$ & \\
\hline Increased & $2(5.7)$ & $2(7)$ & $0(0)$ & \\
\hline
\end{tabular}




\begin{tabular}{|c|c|c|c|c|}
\hline Normal & 232 & & & \\
\hline \multicolumn{5}{|l|}{ Blood Saturation } \\
\hline $\mathrm{pH}$ & $70(47.2)$ & $32(38)$ & $38(60)$ & 0.004 \\
\hline Decreased & $13(8.7)$ & $12(14)$ & $1(1.6)$ & \\
\hline Increased & $65(43.9)$ & $41(48)$ & $24(38)$ & \\
\hline \multicolumn{5}{|l|}{ Normal } \\
\hline PCo2 (mmHg) & $72(48.6)$ & $42(48)$ & $30(49)$ & $>0.9$ \\
\hline Decreased & $43(29.0)$ & $26(30)$ & $17(28)$ & \\
\hline Increased & $33(22.2)$ & $19(22)$ & $14(23)$ & \\
\hline \multicolumn{5}{|l|}{ Normal } \\
\hline HCo3 (meql/L) & $81(54.7)$ & $39(44)$ & $42(70)$ & 0.003 \\
\hline Decreased & $14(9.4)$ & $8(9.5)$ & $6(10)$ & \\
\hline Increased & $53(35.8)$ & $41(46)$ & $12(20)$ & \\
\hline \multicolumn{5}{|l|}{ Normal } \\
\hline Po2 (mmHg) & $90(60.8)$ & $51(58)$ & $39(64)$ & 0.73 \\
\hline Decreased & 19 (12.8) & $11(13)$ & $8(13)$ & \\
\hline Increased & $39(26.3)$ & $25(29)$ & $14(23)$ & \\
\hline \multicolumn{5}{|l|}{ Normal } \\
\hline BE & $113(76.3)$ & $61(73)$ & $52(81)$ & 0.46 \\
\hline Decreased & $17(11.4)$ & $11(13)$ & $6(9.5)$ & \\
\hline Increased & $18(12.1)$ & $12(15)$ & $6(9.5)$ & \\
\hline Normal & 165 & & & \\
\hline \multicolumn{5}{|c|}{ Radiology Results } \\
\hline Chest X-Ray & 232 & & & $<0.001$ \\
\hline Normal & $97(41.8)$ & $67(55)$ & $30(27)$ & \\
\hline Abnormal & $135(58.1)$ & $54(45)$ & $81(73)$ & \\
\hline Chest CT Scan & 205 & & & 0.029 \\
\hline Normal & $71(34.6)$ & $45(42)$ & $26(27)$ & \\
\hline Abnormal & $134(65.3)$ & $62(58)$ & $72(73)$ & \\
\hline
\end{tabular}




\begin{tabular}{|c|c|c|c|}
\hline Treatment & 325 & & 0.15 \\
\hline No medication & $72(22.1)$ & $49(25)$ & $23(18)$ \\
\hline Treated & $253(77.8)$ & $146(75)$ & $107(82)$ \\
\hline \multicolumn{4}{|c|}{${ }^{1}$ Statistics presented: $\mathrm{n}(\%)$} \\
\hline \multirow{2}{*}{\multicolumn{4}{|c|}{$\begin{array}{l}{ }^{2} \text { Statistical tests performed: chi-square test of independence; Fisher's exact test } \\
\text { *: Due to the heterogeneity in some results, the total number of cases for some parameters are less } \\
\text { than } 325 \text { patients. }\end{array}$}} \\
\hline & & & \\
\hline \multicolumn{4}{|c|}{$\begin{array}{l}\text { Abbreviation used: ALT, Alanine aminotransferase; AST, aspartate aminotransferase; BE, Base excess; } \\
\text { BUN, blood urea nitrogen; Ca, Calcium; CF, cystic fibrosis; CPK, Creatinine phosphokinase; CRP, C- } \\
\text { reactive protein; ESR, erythrocyte sedimentation rate; FTT, Failure to thrive; } \mathrm{K} \text {, potassium; } \mathrm{LDH} \text {, lactate } \\
\text { dehydrogenase; Na, Sodium; P, phosphorus; PCO2, Partial pressure of carbon dioxide. PCR= } \\
\text { Polymerase Chain Reaction, PO2= partial pressure of oxygen, PT= Prothrombin Time, PTT= Partial } \\
\text { Thromboplastin Time. }\end{array}$} \\
\hline
\end{tabular}

Table 2. Comparisons between age groups and different clinical outcomes. 


\begin{tabular}{|c|c|c|c|c|c|c|}
\hline Characteristic & All Patients & $\begin{array}{l}0-1, \\
N=57^{1}\end{array}$ & $\begin{array}{l}1-5 \\
N=104^{1}\end{array}$ & $\begin{array}{l}\text { 5-10, } \\
N=70^{1}\end{array}$ & $\begin{array}{l}\text { 10-15, } \\
N=94^{1}\end{array}$ & P-value ${ }^{2}$ \\
\hline Shock & & & & & & $>0.9$ \\
\hline Negative & & $54(95 \%)$ & $98(94 \%)$ & $66(94 \%)$ & 89 (95\%) & \\
\hline Positive & 18 & $3(5.3 \%)$ & $6(5.8 \%)$ & $4(5.7 \%)$ & $5(5.3 \%)$ & \\
\hline Arrhythmia & & & & & & 0.4 \\
\hline Negative & & $55(96 \%)$ & 102 (98\%) & 70 (100\%) & $91(97 \%)$ & \\
\hline Positive & 7 & $2(3.5 \%)$ & $2(1.9 \%)$ & $0(0 \%)$ & $3(3.2 \%)$ & \\
\hline Acute Kidney Injury & & & & & & 0.3 \\
\hline Negative & & $57(100 \%)$ & 103 (99\%) & 67 (96\%) & 91 (97\%) & \\
\hline Positive & 7 & $0(0 \%)$ & $1(1.0 \%)$ & $3(4.3 \%)$ & $3(3.2 \%)$ & \\
\hline ARDS & & & & & & 0.015 \\
\hline Negative & & 49 (86\%) & 102 (98\%) & 65 (93\%) & $84(89 \%)$ & \\
\hline Positive & 35 & $8(14 \%)$ & $2(1.9 \%)$ & $5(7.1 \%)$ & $10(11 \%)$ & \\
\hline Acute Cardiac Injury & & & & & & 0.3 \\
\hline Negative & & $56(98 \%)$ & 102 (98\%) & 65 (93\%) & 91 (97\%) & \\
\hline Positive & 11 & $1(1.8 \%)$ & $2(1.9 \%)$ & $5(7.1 \%)$ & $3(3.2 \%)$ & \\
\hline ICU & & & & & & 0.2 \\
\hline Negative & & $33(58 \%)$ & $71(68 \%)$ & 47 (67\%) & 70 (74\%) & \\
\hline Positive & $\begin{array}{l}104 \\
(32 \%)\end{array}$ & $24(42 \%)$ & $33(32 \%)$ & $23(33 \%)$ & $24(26 \%)$ & \\
\hline Oxygen Therapy & & & & & & 0.3 \\
\hline Negative & & $34(60 \%)$ & $66(63 \%)$ & $39(56 \%)$ & $65(69 \%)$ & \\
\hline Positive & $121(37.2 \%)$ & $23(40 \%)$ & 38 (37\%) & $31(44 \%)$ & $29(31 \%)$ & \\
\hline $\begin{array}{l}\text { Antibiotic } \\
\text { Therapy }\end{array}$ & & & & & & $>0.9$ \\
\hline Negative & & $13(23 \%)$ & $19(18 \%)$ & $13(19 \%)$ & $18(19 \%)$ & \\
\hline Positive & & 44 (77\%) & 85 (82\%) & 57 (81\%) & 76 (81\%) & \\
\hline Death & & & & & & 0.4 \\
\hline
\end{tabular}




\begin{tabular}{|llllll|} 
Negative & & $46(81 \%)$ & $93(89 \%)$ & $62(89 \%)$ & $79(84 \%)$ \\
\hline Positive & 45 & $11(19 \%)$ & $11(11 \%)$ & $8(11 \%)$ & $15(16 \%)$ \\
\hline
\end{tabular}

Table 3. Comparison of the presence and absence of comorbidities between pediatrics patients and association with clinical outcomes. 


\begin{tabular}{|c|c|c|c|}
\hline Characteristic & $\begin{array}{l}\text { No Comorbidity } \\
\mathrm{N}=190^{1}(\%)\end{array}$ & $\begin{array}{l}\text { Comorbidity } \\
\mathrm{N}=135^{1} \text { (\%) }\end{array}$ & P-value ${ }^{2}$ \\
\hline Shock & & & 0.003 \\
\hline Negative & $186(98)$ & $121(90)$ & \\
\hline Positive & $4(2.1)$ & $14(10)$ & \\
\hline Arrhythmia & & & 0.13 \\
\hline Negative & $188(99)$ & $130(96)$ & \\
\hline Positive & $2(1.1)$ & $5(3.7)$ & \\
\hline Acute Kidney Injury & & & 0.13 \\
\hline Negative & $188(99)$ & $130(96)$ & \\
\hline Positive & $2(1.1)$ & $5(3.7)$ & \\
\hline ARDS & & & $<0.001$ \\
\hline Negative & $184(97)$ & $116(86)$ & \\
\hline Positive & $6(3.2)$ & $19(14)$ & \\
\hline Acute Cardiac Injury & & & 0.057 \\
\hline Negative & $187(98)$ & $127(94)$ & \\
\hline Positive & $3(1.6)$ & $8(5.9)$ & \\
\hline ICU & & & 0.003 \\
\hline Negative & $142(75)$ & $79(59)$ & \\
\hline Positive & $48(25)$ & $56(41)$ & \\
\hline Oxygen & & & 0.6 \\
\hline Negative & $122(64)$ & $82(61)$ & \\
\hline Positive & $68(36)$ & $53(39)$ & \\
\hline Antibiotic & & & 0.3 \\
\hline Negative & $41(22)$ & $22(16)$ & \\
\hline Positive & 149 (78) & $113(84)$ & \\
\hline Death & & & $<0.001$ \\
\hline Negative & $181(95)$ & $99(73)$ & \\
\hline Positive & $9(4.7)$ & $36(27)$ & \\
\hline
\end{tabular}


Table 4. Different drug regimen in relation with illness severity.

\begin{tabular}{|c|c|c|c|c|}
\hline Characteristic & $\mathbf{N}(\%)$ & $\begin{array}{l}\text { Moderate, } \\
\begin{array}{l}\mathrm{N}=195^{1} \\
(\%)\end{array}\end{array}$ & $\begin{array}{l}\text { Severe, } \\
\begin{array}{l}\mathrm{N}=130^{1} \\
(\%)\end{array}\end{array}$ & $\begin{array}{l}\text { P- } \\
\text { value }^{2}\end{array}$ \\
\hline No Treatment & $72(22.2)$ & $49(25)$ & $23(18 \%)$ & \\
\hline Treatment Medication & $\begin{array}{l}253 \\
(77.8)\end{array}$ & & & $<0.001$ \\
\hline Hydroxychloroquine & $99(30.4)$ & $66(34)$ & $33(25)$ & \\
\hline Hydroxychloroquine Kaletra & $38(11.7)$ & $20(10)$ & $18(14)$ & \\
\hline Hydroxychloroquine Kaletra Naproxen & 1 & $1(0.5)$ & $0(0)$ & \\
\hline Hydroxychloroquine Kaletra Oseltamivir & 12 & $3(1.5)$ & $9(6.9)$ & \\
\hline $\begin{array}{l}\text { Hydroxychloroquine Kaletra Oseltamivir } \\
\text { Ribavirin }\end{array}$ & 4 & $0(0)$ & $4(3.1)$ & \\
\hline Hydroxychloroquine Kaletra Ribavirin & 4 & $0(0)$ & $4(3.1)$ & \\
\hline Hydroxychloroquine Naproxen & 2 & $1(0.5)$ & $1(0.8)$ & \\
\hline Hydroxychloroquine Naproxen Oseltamivir & 1 & $1(0.5)$ & $0(0)$ & \\
\hline Hydroxychloroquine Oseltamivir & $44(13.5)$ & $34(17)$ & $10(7.7)$ & \\
\hline Hydroxychloroquine Oseltamivir Ribavirin & 2 & $0(0)$ & $2(1.5)$ & \\
\hline Hydroxychloroquine Ribavirin & 1 & $1(0.5)$ & $0(0)$ & \\
\hline Kaletra & 7 & $3(1.5)$ & $4(3.1)$ & \\
\hline Kaletra Oseltamivir & 9 & $3(1.5)$ & $6(4.6)$ & \\
\hline Kaletra Ribavirin & 1 & $0(0)$ & $1(0.8)$ & \\
\hline Naproxen Oseltamivir & 1 & $1(0.5)$ & $0(0)$ & \\
\hline Oseltamivir & 27 & $12(6.2)$ & $15(12)$ & \\
\hline${ }^{1}$ Statistics presented: n (\%) & & & & \\
\hline
\end{tabular}

\section{Figures}




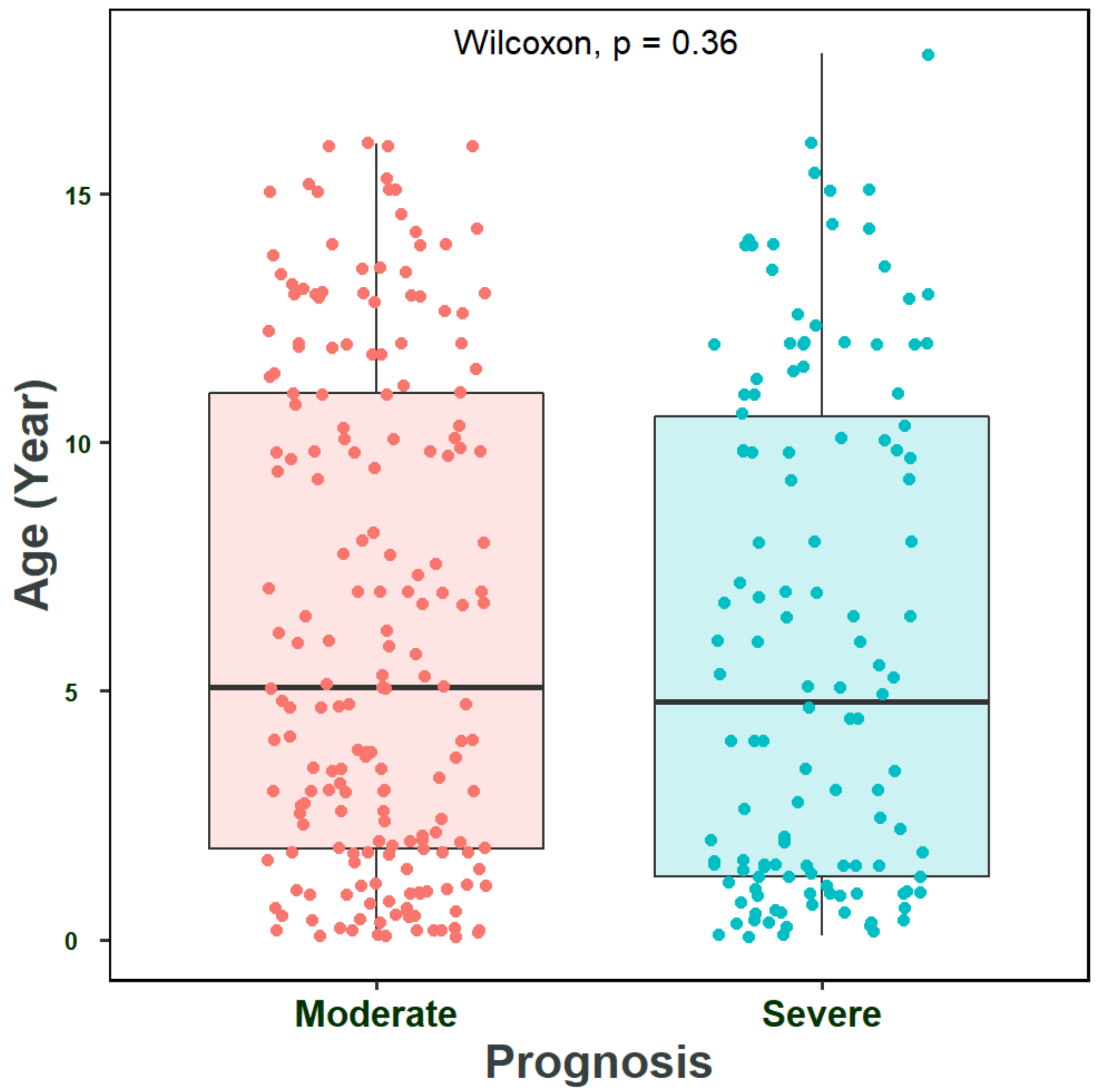

Figure 1

Correlation between different age groups and illness severity. 